\title{
物理化学课程思政教学设计与实践
}

孙艳辉 ${ }^{*}$ 南俊民，马国正，何广平，左晓希，李国良，林晓明

华南师范大学化学学院, 广州 510006

摘要: 推进专业课程与思政教育融合是落实高校立德树人的根本。物理化学作为化学类核心专业基础课程, 对学生 的培养起着至关重要的作用。依据课程思政内涵, 结合物理化学课程教学目标, 从学科发展史、科学家简介、经典理 论和方法、学科交叉、科学发展前沿以及物理化学在生产生活中的应用等 6 个方面挖掘梳理课程蕴含的思政教育要点, 并进行相应的教学设计。同时给出了课程思政教学实践模式和评价方法。

关键词: 物理化学; 课程思政; 教学设计; 教学实践; 教学评价

中图分类号: G64; O6

\section{Design and Practice of Course Ideology and Politics in Physical Chemistry}

\author{
Yanhui Sun ", Junmin Nan, Guozheng Ma, Guangping He, Xiaoxi Zuo, Guoliang Li, Xiaoming Lin \\ School of Chemistry, South China Normal University, Guangzhou 510006, China.
}

\begin{abstract}
The integration of professional courses and ideological and political education is the fundamental task of moral education in colleges and universities. Physical chemistry, as the core professional course of chemistry, plays an important role in the cultivation of students. In this study, based on the concept of course ideology and politics and the teaching objectives of physical chemistry, possible points for ideological and political education in the course are explored from the following six aspects: the history and development of the discipline, resumes of scientists, classical theories and methods, interdisciplinary knowledge, the frontiers of physical chemistry and science and technology, and applications of physical chemistry in production and life. Meanwhile, teaching designs, practice modes, and evaluation methods of course ideology and politics are proposed.
\end{abstract}

Key Words: Physical chemistry; Course ideology and politics; Teaching design; Teaching practice; Teaching evaluation

2016年习近平总书记在全国高校思想政治工作会议上强调, 思想政治工作要贯穿教育教学全过 程, 各类课程要与思政理论课同向同行, 形成协同效应。之后高校 “课程思政” 建设形成高潮 ${ }^{[1-3]}$ 。 目前, “课程思政” 已经全面纳入本科教学新体系 ${ }^{[4-7]}$, 华南师范大学也全面开展了专业课程思政教 学。

物理化学是化学学科的理论基础, 对提高学生的专业技能、逻辑思维能力、数理能力、思辩能 力、综合运用知识能力等都具有重要作用。该课程涉及很多抽象的概念和原理、繁杂的数学公式推

收稿: 2020-10-12; 录用: 2020-11-11; 网络发表: 2020-12-01

“通讯作者, Email: sunyanhui0102@163.com

基金资助: 华南师范大学线上、线下混合一流精品课程; 华南师范大学质量工程项目: 物理化学课程思政教学设计与实践; 广东省在线开放 课程 
导等, 在传统教学中教师更多把教学重点放在知识传授, 而忽视了育人。针对如何挖掘课程中的思 政教学要点, 有效地开展课程思政教育, 近年来本教学团队从以下几方面进行了研究与实践。

\section{1 确定物理化学课程思政教育的基本原则和基本切入点}

\section{1 物理化学课程思政教育的基本原则}

结合课程思政内容的几个维度, 从物理化学课程教学大纲的教学目标梳理课程可能蕴含的思政 要点。张树永教授给出了课程思政的7个维度 ${ }^{6]}$, 即: 政治方向正确、德才兼备、正确的世界观和科 学的方法论、科学文化修养、家国情怀、文化传承和文化自信、国际视野。

按照化学师范专业认证标准, 教学团队制定了适用于化学(师范)专业的物理化学课程教学的 8 个 目标: (1) 了解物理化学的建立与发展的历史和趋势, 掌握物理化学研究的基本内容, 了解物理化学 学科中所渗透的自然科学研究方法, 树立辩证唯物主义世界观; (2) 掌握物理化学的基本概念、原理 及其应用, 了解物理化学与其他学科的交叉关系; (3) 了解物理化学在生产、生活和科学研究中的应 用, 能用物理化学的原理和知识解决生产生活中遇到的实际问题; (4) 形成和建立科学的学习方法 和思维习惯, 具备逻辑推理、归纳分析、模型假设、数理统计等思维能力, 从而能胜任化学及相关 领域科研、教学及其他工作; (5) 学会认识和探究化学变化的本质, 整合其他分支化学, 形成完整的 化学理论知识体系, 从而具备良好的化学学科素养; (6) 具有分析、处理中学化学教材中与物理化学 知识相关内容的能力, 做好大学化学与中学化学教学的衔接, 融会贯通地渗透于中学化学教育; (7) 能自主学习物理化学理论在科学前沿领域的研究进展, 适应时代和教育发展需求; (8) 能够在物 理化学课程小组学习过程中, 学会合作和沟通, 具有团队协作精神。

依据上述课程思政教学目标的 7 个维度, 结合物理化学课程大纲的 8 个教学目标, 在教学实践中, 教学团队按照物理化学课程内容和特点, 分别从以下 6 个方面挖掘课程思政内容, 如图1所示。

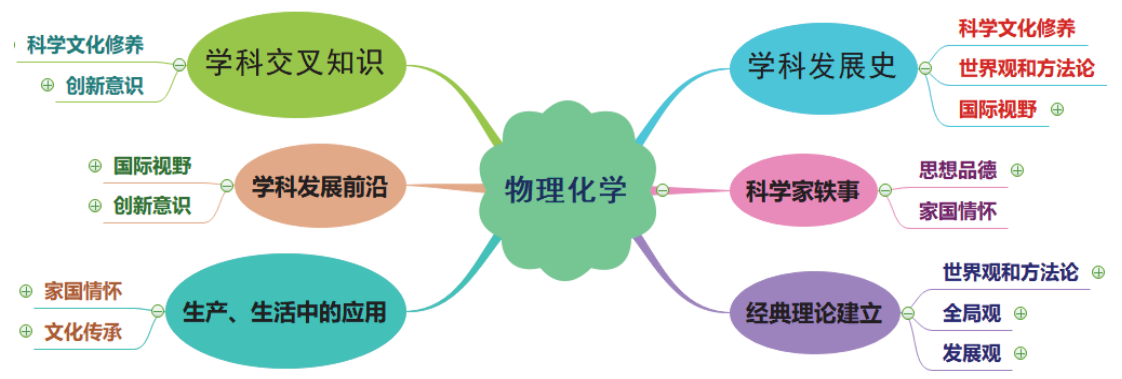

图 1 物理化学中的课程思政设计要点

\section{2 物理化学课程思政教育的基本切入点}

按照课程思政 7 个维度和教学大纲的 8 个培养目标确定了如下 6 个思政教育的切入点:

(1) 学科发展史: 通过物理化学学科发展简史的学习, 渗透科学的世界观、方法论; 帮助学生形 成科学文化素养。

(2) 科学家简介: 通过物理化学家的生平轶事、科研贡献简介, 培养学生坚韧不拔、勇攀科学高 峰的精神, 体会科学家的个人奋斗与国家社会发展的关系。

(3) 经典理论和方法: 物理化学被誉为 “化学中的哲学”, 在学科思维教育方面独具鬼力。经典 物理化学中的各种定律和理论的形成, 各种理想模型的建立和公式的推导, 渗透着丰富的方法论和 科学的世界观; 在学习不断发展完善的理论过程中，体会全局观、发展观。

(4) 学科交叉知识: 物理化学用数学和物理的方法解决化学问题, 与分析化学、有机化学、生物、 医药、材料、农林等学科都有交叉, 可以基于此培养学生的创新意识, 提高学生的科学文化素养。

(5) 物理化学与科学发展前沿: 通过学习物理化学在新材料、新能源、生命医药等领域的应用, 
以及经典物理化学的新进展, 培养学生的国际视野和创新意识。

(6) 物理化学在生产生活中的应用: 可以注重中国元素介绍, 将中国传统文化和人民日常生活 中的智慧与物理化学教学相联系。培养学生的家国情怀和文化传承。

\section{2 梳理挖掘物理化学课程思政内容及教学设计}

按照物理化学的四大知识板块: 热力学、动力学、电化学、胶体与界面化学分别梳理, 将每一 知识板块分别从图1所示的 6 个要点去挖掘适合开展思政教育的知识点, 并进行相应的教学设计。具 体如下。

\section{1 从学科发展史和学科前沿渗透课程思政内容}

物理化学的每一分支的发展历程几乎都经历了从实践到理论, 再回归实践的过程。由于科学技术 的制约, 在学科发展进程中出现了一些违反科学事实的观点, 但最终被科学事实推翻。例如在热力学 发展史中, 热力学第一、第二、第三定律都是首先来自于大量的经验结果, 而后才有了严谨的数学公 式, 也曾出现过第一、二类永动机、热死论、麦克斯韦妖等违背科学事实的观点。目前则发展了非平衡 态热力学。表面和胶体物理化学知识体系的形成和发展, 将人们的视野从宏观、微观引入了介观世界。

通过上述物理化学学科建立和发展史的学习, 学生可以了解某些学科知识如何适应社会发展而发 生和发展, 渗透个人发展与社会发展的协调统一; 学科史的学习可以启迪学生的思维和智慧, 培养学 生科学探索的精神。对一些违背科学事实观点的了解, 可以培养学生的批判性思维, 形成正确的世界 观和科学的方法论; 通过介绍物理化学各分支目前发展的前沿热点问题, 开阔学生视野, 提高学生的 科学文化素养, 增强创新意识。通过介绍中国科学家在科学前沿取得的成绩, 激发学生的民族自豪感 与爱国热情。

\section{2 从科学家轶事渗透课程思政内容}

在物理化学各分支发展进程中, 涌现了大批贡献卓著的科学家, 有些甚至对整个物理化学学科的 贡献都是不可磨灭的。例如汤姆逊(开尔文)、吉布斯、能斯特、范特霍夫、阿伦尼乌斯、奥斯特瓦尔德 等的贡献涉及物理化学多个分支。而一些科学家如亥姆霍兹、法拉第等由于经济原因并未接受过高等 教育, 却依靠自身努力在多学科做出卓越贡献。授课中重点介绍中国的物理化学家如何在艰苦的科研 环境和生活条件下, 依然在各领域进行开创性研究, 为提升中国在世界的竞争力做出杰出贡献, 以此 增强学生的民族自豪感和自信心, 渗透爱国情怀。例如: 黄子卿教授对水的三相点进行了精确测定; 梁 敬鬼先生系统地测定了大量相图, 被国内外相图汇编收集, 并在中国推进了相图在单晶生长中的应用。 李远哲(美籍华人)教授在化学动力学、动态学、分子束及光化学等方面贡献卓著; 张存浩教授是中国高 能化学激光奠基人、分子反应动力学奠基人。彭少逸教授为中国催化化学的开拓者。张大显先生提出

“表面键” 催化理论, 推动催化动力学的发展。李方训教授长期从事电解质溶液性质及理论的研究, 对离子熵、离子的极化和半径以及混合电解质溶液中离子活度系数等做出了贡献。傅鹰先生作为中国 胶体表面化学创始人提出了表面化学的吸附理论, 利用润湿热测定固体粉末比表面的公式和方法, 比 著名的BET (Brunauer-Emmett-Teller)气体吸附法早8年。

通过了解在物理化学发展进程中做出突出贡献的国内外科学家的生平事迹, 学习科学家们如何在 科学道路上孜孜以求, 激发学生发奋图强、追求真理的精神。通过了解科学家们如何尊重实验事实、发 现问题、严谨求真、在科研道路上走向顶峰的事迹, 激发学生的创新思维, 培养学生实事求是、严谨的 科学态度以及探究事物本质的能力。

\section{3 从物理化学经典理论和方法中渗透课程思政内容}

物理化学涉及热力学、动力学、电化学、胶体与表面化学等多个经典理论和相关的解决问题的方 法。如热力学三大定律、盖斯定律、基尔霍夫定律、Gibbs相律等热力学理论和方法; 动力学中解决简 单级数速率方程的方法; 利用速控步法、平衡假设法、稳态近似法在拟定反应历程的方法中的应用; 电 化学中涉及的拉第电解定律、离子独立移动定律、电解质溶液理论、电池电动势的能斯特方程、可逆电 
池解决热力学问题、对消法测定原电池电动势的原理等; 胶体的稳定性理论、空间稳定、空位稳定理论 等。

物理化学为解决问题, 提出了很多理想模型和解决问题的方法, 如理想气体、理想溶液; 可逆过 程、卡诺热机; 可逆电池、标准氢电极等理想模型。

通过物理化学经典理论和研究方法的学习, 渗透唯物论和辩证法教育, 推进对马克思主义世界观 和方法论的理解。在对各种理想模型认知基础上, 学习解决实际问题的方法, 培养学生建构模型的能 力和解决问题的方法。通过对各经典理论从初步形成、发展到逐渐成熟的学习, 以及对各板块内容知 识的系统性、衔接性的理解, 培养学生具备缜密的逻辑思维能力, 严谨的治学态度和作风, 以及看待事 物的全局观和发展观。

\section{4 从物理化学与学科交叉及其在生产、生活实际的应用渗透课程思政内容}

物理化学这一学科从诞生之初就注定了其在多学科的交叉应用以及为生产生活服务。例如: 热力 学中热机效率、冷冻系数的知识在内燃机、空调、冰箱等方面的应用。低温热棒在青藏铁路建设中的应 用。相图在蒸馏、结晶、萃取、冶金熔炼等行业的应用。凝固点降低在医学和冷冻液方面的应用; 渗透 压在工业上用于反渗透净化海水、在医疗中用于血液透析、生活中腌制食品等; 超临界干燥技术、超临 界萃取等在材料制备提纯行业的应用。动力学中: 飞秒激光化学在医疗领域的应用; 放射性碳测年代 在考古、刑侦中的应用。电化学中的电池制造、电解冶炼、电镀生产等; 电化学分析、电化学传感器在 各行各业的应用。表面化学: BET吸附在比表面积、孔体积测定中的应用; 润湿现象、表面活性剂用于 矿物浮选、石油开采、洗涤产品的应用; 微乳法、溶胶凝胶法合成纳米材料。胶体化学: 气溶胶-雾皬 的形成; 电泳电渗在工业中的应用; 流动电势、沉降电势的潜在危害。荷叶效应-超疏水现象在仿生材 料合成中的应用。

在教学中, 通过了解物理化学理论在其他学科、日常生活以及生产中的具体应用, 尤其是体现中 国劳动人民智慧的一些应用, 以及我国首创或具有自主知识产权的技术, 培养学生的创新意识, 激发 他们的爱国情怀和民族自豪感。例如中国自己的冻土治理技术一一低温热棒, 成功解决了 40 多年来困 扰科学家和青藏铁路建设者的重大技术难题——青藏铁路路基多年冻土层夏季融沉、冬季冻胀的不稳 定问题。在一些应用中引入中国传统文化, 尤其是诗词歌赋, 意境优美。例如讲授液-固表面润湿现象, 以宋代周敦臨的 “爱莲说” 中 “予独爱莲之出淤泥而不染, 濯清涟而不妖” 和南朝徐陵的 “侍宴诗” 中

“嫩竹犹含粉, 初荷未聚尘”, 作为导课资料, 引领学生学习固体表面润湿、亲水与疏水知识, 激发学 生学习兴趣, 使学生既感受到文化的熏陶, 又能开拓学科视野 ${ }^{[7]}$ 。介绍气溶胶形成雾霧、携带细菌病毒 传染疾病等事实, 培养学生的环保意识和社会责任感。

\section{5 课程思政内容教学设计}

上述课程思政内容要点的渗透, 在教学中可以灵活运用多种方式: 如以文献阅读方式, 要求学生 结合百年诺贝尔化学奖了解物理化学相关获奖项目, 撰写进展报告或调研报告, 在文献阅读中感受科 学家探索科学、执着真理的精神; 可以利用在线课程的拓展资源在线学习有关课程思政内容的资料: 由于线下学时有限, 教师提前将具有思政元素的资料上传至在线课程平台的拓展资源版块供学生学习; 可以结合案例分析进行小组讨论, 例如对于一些工业生产、生活实际中运用了物理化学的某些原理的 案例, 尤其是中国科学家首创的发明或设计等, 安排学生分组讨论其如何利用物理化学原理解决问题, 及其重要意义; 可以引用一些课程思政的实例进行导课等。

\section{3 教学实践与教学效果评价}

基于 “以学生为中心” “以产出为导向” 的理念进行教学设计和实施 ${ }^{[6]}$ 。按照物理化学课程章 节, 结合相关内容, 分别在课程的不同阶段, 采用不同教学方式开展课程思政教学和教学评价, 如 图2所示。在具体教学实践中, 分别在课程导言、课程拓展、单元知识体系构建、课程理论讲授等多 个环节, 灵活地融入课程思政内容, 在学科内容方面做到详略得当、突出知识主干, 重难点精讲, 
强调实际应用; 并以小组合作学习、文献阅读、线上-线下混合学习等方式开展课程思政教学。例如: 案例一: 在绪论课教学中, 我们会布置一项专题论文写作, 要求学生结合互联网资源, 了解在百年 诺贝尔化学奖的奖项中与物理化学知识有关的内容, 并择其一进行简要阐述。通过该项作业, 帮助 学生了解学科发展的进程, 启迪学生智慧, 并从中学习科学家的探索精神, 为后续学习打下坚实的 基础, 提高学生的文化修养并开拓学生的国际视野。案例二: 在热力学第二定律结束后, 布置作业: 了解青藏铁路热棒工作原理, 并用热力学第二定律知识进行解释。该项作业既对学生进行了爱国主 义教育, 又做到了学以致用。图3、图4分别给出了学生完成作业记录情况。

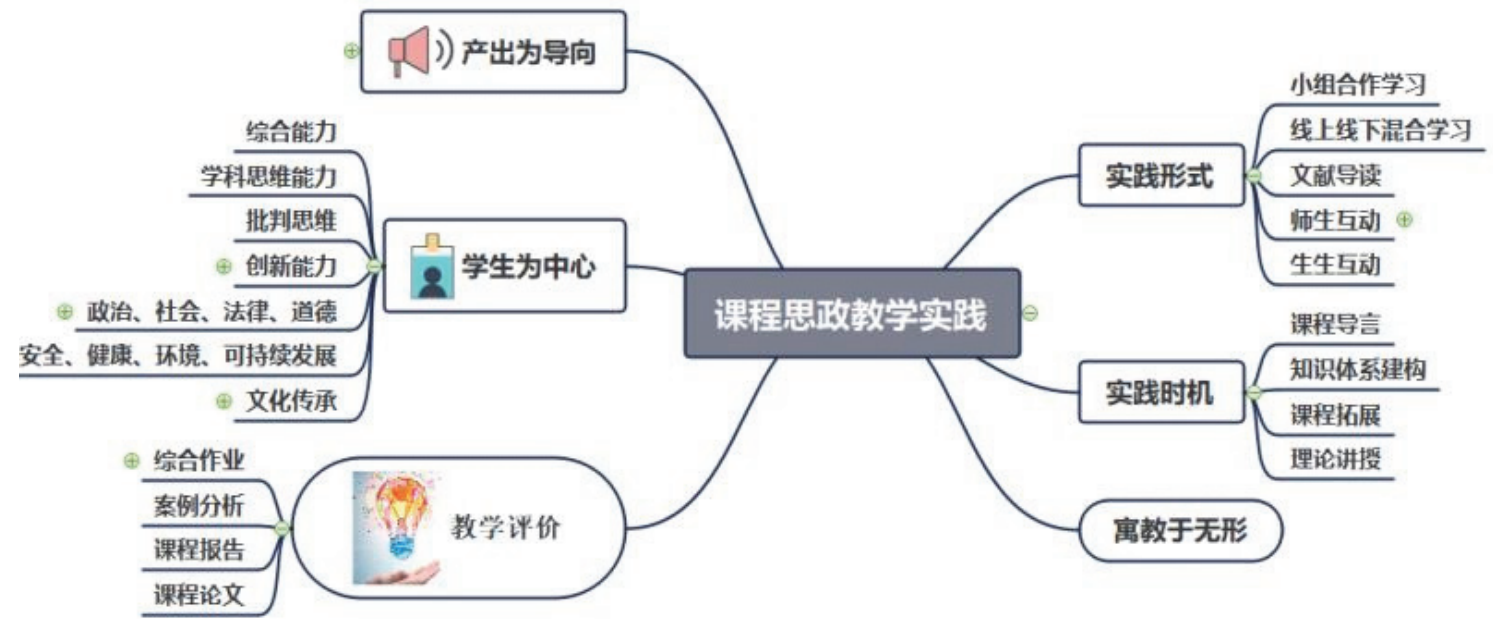

图2 课程思政教学实践模式

首页 > 我的淉保 > 2019 级新能原 (物理化学 (1) ) > 第一童绪 论 > 小貉文

小论文

请同学们查阅文献，了解百年来诺贝尔化学奖中与物理化学相关的内容，并选择1 2个具体 奖项进行较详细的闸述。不少于500字。截止日期：2020年10月7日23：59分。

满分: 100分。

\section{评分概要}

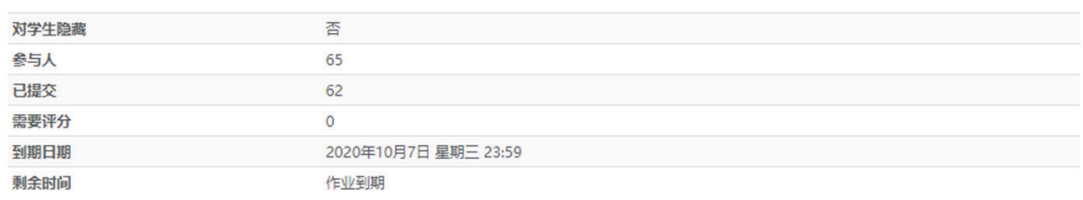

图3 课程思政教学案例一

对课程思政教学效果的评价, 突出评价学生综合能力、学科思维能力和批判创新能力, 推动专 业教学由知识导向型向能力和素质导向型转变。

学生利用在课内外习得的知识、能力和素质进行正确的分析和判断, 在提出科学研究或者技术 开发方案时能够综合考虑政治、社会、法律、道德、安全、健康、文化以及环境和可持续发展等因 素的影响，正确理解个人的义务和责任，是课程思政教育成功的根本标志。

评价课程思政效果时需要采用结果导向模式。利用综合作业、案例分析、方案设计、课程报告 (含进展报告、调研报告、研究报告等)和课程小论文等体现结果的形式进行评价。例如, 通过图3所 示的课程作业可以评价课程思政教学的效果。另外, 也在期中或期末考试中设计一些带有思政元素 的题目或小论文，考查学生的思维能力与分析问题的能力。 
热力学第二定律作业- “从青藏铁路热棒工作原理谈谈热力学第二定律"

理论联系实际是人类认识或学习活动的普遍规律之一。请同学们根据以下资料了解热力学第 二定律的具体应用，学习我国科技工作者的创新能力。

青藏铁路冻土带路段 (即含水量较高土质) 的路基受大气昼夜气温剧烈变化的影响、或受大 气升温影响路基受热软化，将会导致路基凸起、开裂、泛浆或塌陷，造成铁轨变形、进而火 车脱轨酿成行车事故. 为避免上述问题，采取的防护措施之一就是用 “热棒技术” 保持路基稳 定的固化状态。

“热棒技术" 原理：热棒是一个细长、密封的钢制圆筒，总长约为 $7 \mathrm{~m}$ ，直径约 $20 \mathrm{~cm}$ 。其中 $5 \mathrm{~m}$ 深插冻土内，为蒸发段，在蒸发段的圆筒内盛有液氨; 其余 $2 \mathrm{~m}$ 暴露在大气中，称为冷凝 段，冷凝段圆筒外壁上设置许多散热片。热棒通过圆筒内氨的液-气转化，把由大气升温转入 冻土的热量又返回给大气，防止冻土因昼夜气温变化或受大气升温影响使其受热升温而软 化，以保持冻土带的固化状态。

(1) 试根据上述 “热棒技术” 原理的叙述，画出 “热棒工作原理图 “，即在热棒作用下，热 在冻土与大气间的循环示意图。(10分)

(2) 试通过热棒工作过程分析热棒是否违反热力学第二定律,为什么? (10分)

(3) 是否可用氮气代替氨做热棒中的传热介质? (10分)

说明: 青藏铁路唐古拉山段 (路长5.5 km) 附近气候特点: 该路段气温夏升冬降，夏季最高 气温为摄氏40度，冬季最低气温为摄氏 -38.6 度，并且昼夜温差变化很大。

液氨的沸点-33.5摄氏度; 液氮的沸点-196.56摄氏度。

\section{评分概要}

\begin{tabular}{ll}
\hline 对学生隐藏 & 否 \\
\hline 参与人 & 176 \\
\hline 已提交 & 114 \\
\hline 需要评分 & 0 \\
\hline 到期日期 & 2016年12月2日 星期五 00:00
\end{tabular}

图4 课程思政教学实践案例二

\section{4 结语}

以思政教育的 7 个维度为根本, 结合物理化学教学目标梳理了 6 个思政教育的切入点, 按照物理 化学知识模块分别列举了每个切入点的教学实例。同时对开展思政教学的实践模式和思政教学效果 评价方法进行了分类，为实现专业课程融入思政教育立德树人的目标提供借鉴和参考。

\section{参 考 文 献}

[1] 习近平在全国高校思想政治工作会议上强调把思想政治工作贯穿教育教学全过程, 开创我国高等教育事业发展新局面. 光明日报, 2016-1209 (1).

[2] 习近平. 紫光阁, 2018, No. 10, 8 .

[3] 陈宝生. 时事报告(党委中心组学习), 2018, No. 10, 18.

[4] 戚传松, 荣华, 李巍, 佟拉嘎. 教育教学论坛, 2020, No. 15, 48.

[5] 边绍伟, 沈丽, 张健, 赵亚萍, 咸春颖. 纺织服装教育, 2019, 34 (5), 443.

[6] 张树永. 大学化学, 2019, 34 (11), 4.

[7] 王旭珍, 王新平, 王新葵, 田福平, 田东旭, 陈冰冰. 大学化学, 2019, 34 (11), 77. 